\title{
BMJ Open Association of inpatient hospital experience with patient safety indicators: a cross-sectional, Canadian study
}

\author{
Kyle A Kemp, ${ }^{1,2}$ Maria J Santana, ${ }^{1}$ Danielle A Southern, ${ }^{1}$ Brandi McCormack, ${ }^{2}$ \\ Hude Quan ${ }^{1}$
}

To cite: Kemp KA, Santana MJ, Southern DA, et al. Association of inpatient hospital experience with patient safety indicators: a cross-sectional,

Canadian study. BMJ Open 2016;6: 011242. doi:10.1136/bmjopen-2016011242

- Prepublication history for this paper is available online. To view these files please visit the journal online (http://dx.doi.org/10.1136/ bmjopen-2016-011242).

Received 22 January 2016 Revised 2 May 2016 Accepted 10 June 2016

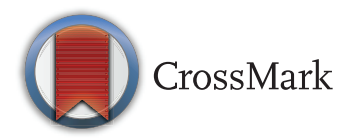

\footnotetext{
${ }^{1}$ Department of Community Health Sciences, Cumming School of Medicine, University of Calgary, Calgary, Alberta, Canada 2Primary Data Support, Analytics (DIMR), Alberta Health Services, Calgary, Alberta, Canada
}

Correspondence to Kyle A Kemp; kkemp@ucalgary.ca

\section{ABSTRACT}

Objectives: There remains concern regarding the use of survey data to assess aspects of healthcare quality. The relationship between patient experience and adverse events as documented by patient safety indicators (PSIs) is a timely research topic. The objectives were to document the association of PSIs and patient experience scores, and to determine riskadjusted odds of high experience scores versus PSI presence.

Setting and participants: From April 2011 to March 2014, 25098 patients completed a telephone survey following discharge from 93 inpatient hospitals in Alberta, Canada.

Research design: A modified version of the Hospital Consumer Assessment of Healthcare Providers and Systems (HCAHPS) instrument was used. Surveys were linked to inpatient records and PSI presence was documented using a validated algorithm.

Measures: Three questions about overall hospital, physician and nurse ratings were scored on an 11-point Likert scale from 0 (worst) to 10 (best). Experience was classified as high (9 or 10) versus low $(0-8)$. Demographic/clinical differences between respondents with/without a PSI were assessed. Logistic regression examined the relationship between factors including PSI and experience ratings.

Results: Overall, physician and nurse care was rated high by $61.9 \%, 73.7 \%$ and $66.2 \%$ of respondents. 1085 patients (4.3\%) had a documented PSI. Most frequent PSIs were haemorrhagic events $(n=502 ; 2.0 \%$ of sample), events relating to obstetrics ( $n=373 ; 1.5 \%)$ and surgical-related events $(\mathrm{n}=248 ; 1.0 \%)$. Riskadjusted models showed patients with PSIs had decreased odds of having high overall ( $\mathrm{OR}=0.86 ; 95 \%$ $\mathrm{Cl} 0.75$ to 0.97 ), physician (OR=0.76; $95 \% \mathrm{Cl} 0.66$ to 0.87 ) and nurse (OR=0.83; $95 \% \mathrm{Cl} 0.73$ to 0.94 ) ratings.

Conclusions: There is clear evidence that inpatient experience ratings are associated with PSIs, one element of quality of care. Future research, examining individual PSIs and patient experience questions, is warranted, as this may inform targeted quality improvement initiatives.
Strengths and limitations of this study

- This study examined the association of patient safety indicators (PSIs) and patient experience scores, as documented by the Hospital Consumer Assessment of Healthcare Providers and Systems (HCAHPS), a validated survey.

- PSIs were documented using a validated administrative data algorithm. This is a significant advantage over chart reviews, which are time consuming and may be prone to subjective error.

- Although administrative data alone may not capture all PSIs, their accepted use as a quality indicator has been documented by several organisations, including the Agency for Healthcare Research and Quality (AHRQ).

- The association between patient-reported hospital experience and PSIs lends credibility to the inclusion of patient experience as a reliable, patient-reported account of what occurred in-hospital.

- PSIs represent only one aspect of quality of care. Future research which examines the association of patient experience and other aspects of quality of care is warranted.

In recent years, patient-centred care (PCC) has emerged as a key priority for health systems and patients alike. Indeed, the Institute of Medicine considers PCC as one of six key elements of high-quality care. ${ }^{1}$ Although there is no common definition of PCC, the underlying principle is to engage patients, allowing them to be active participants in their own care. In addition to a clinical emphasis, PCG is the focus of emerging research groups, including the Patient-Centered Outcomes Research Institute (PCORI; USA) ${ }^{2}$ and the Strategy for Patient-Oriented Research (SPOR; Canada). ${ }^{3}$

Despite this, there remains scepticism as to whether patients possess the ability to accurately assess the quality of their care. 
A common method for assessing the perceived quality of healthcare services on the part of patients is to administer a hospital experience survey. In their own right, patient experience surveys offer tremendous value from a quality improvement perspective. Organisations can receive feedback directly from their patients and use the data to guide targeted improvement efforts. ${ }^{4}$ One drawback of this approach, however, is that surveys are a passive means of assessing quality of care, and that patient experience has been thought to be more reflective of the patient's general mood or subjective response tendencies. ${ }^{5}$ As gaps in communication may exist between physicians and their patients, it is also acknowledged that patients may not be aware of all medical decisions made on their behalf. In short, when patients report their hospital experience, they may not be making an informed assessment. Thus, evidence to show that patient reports of their hospital experience are associated with other outcomes such as measures of quality of care would help to counter this potential misconception.

Preliminary research has explored the relationship between patient experience and outcomes, with conflicting results. One large, national study showed that a better patient experience was associated with greater inpatient healthcare use, higher overall and prescription drug expenditures, and increased mortality. ${ }^{6}$ On the other hand, higher patient satisfaction has been associated with better outcomes among those with acute myocardial infarction, congestive heart failure and pneumonia. ${ }^{7-9}$ It has also been associated with fewer complications ${ }^{10}{ }^{11}$ and adverse events (AEs). ${ }^{12}$ Kennedy et $a \bar{l}^{\tilde{p}}$ found that better patient satisfaction was associated with lower mortality but was not correlated with compliance with process measures or length of stay. A systematic review ${ }^{13}$ highlighted conflicting results with respect to patient experience and its association with various measures of patient safety. Although it was more common to find positive associations between the two, ${ }^{13}$ conflicting results may be in part due to variations in the size of the study, the cohort studied (eg, demographics, clinical profile), the context (eg, inpatient, emergency department, primary care) and the methods used to document patient experience.

Although they are similar terms which are oftentimes used interchangeably, it is important to understand the differences between patient satisfaction and patient experience. Jason A. Wolf, President of the Beryl Institute, a global community of practice dedicated to improving the patient experience, states that satisfaction is 'the idea of how positive someone feels about an encounter'. ${ }^{14}$ Experience encompasses more than a sense of satisfaction and is defined in all that is perceived, understood and remembered'. ${ }^{14}$ Patient experience is 'about ensuring the best in quality, safety and service outcomes'. ${ }^{14}$ It can assess aspects of PCC such as the inclusion of the patient in care decisions, as well as issues such as patient understanding of their condition/ treatment and discharge instructions.
Having standardised methods to document quality of care and patient experience is essential. Patient safety indicators (PSIs) are a validated means to use administrative data in order to document in-hospital AEs. ${ }^{15-21}$ In the Canadian context, a comprehensive list of PSIs has been developed and validated by our research group, using the Canadian version of the International Classification of Diseases (ICD), 10th revision (ICD-10-CA) (DA Southern, H Quan, WA Ghali. Deriving ICD-10 codes for patient safety indicators for large-scale surveillance using administrative data. Submitted). ${ }^{21}$ For documenting inpatient hospital experience, the Hospital Consumer Assessment of Healthcare Providers and Systems (HCAHPS) is a validated, standardised instrument. It is the current gold standard in the USA, where it is mandated under the US Affordable Care Act. ${ }^{22-24}$ Literature documenting the association between PSIs and patient experience, as documented by HCAHPS, has been non-existent to date. Forster et $a l^{25}$ used a similar survey methodology to demonstrate an association between patient experience and adverse drug events posthospital discharge. This study, however, did not use HCAHPS, but rather an ad hoc survey.

We sought to (1) document the association of PSIs and patient experience scores, as documented by HCAHPS and (2) determine the risk-adjusted odds of high overall, physician and nurse-related experience scores compared with PSI presence.

\section{METHODS}

\section{Study population}

From April 2011 to March 2014, 27492 respondents completed an HCAHPS-based patient experience survey within 6 weeks of discharge in the province of Alberta, Canada. This number represents $5.6 \%$ of the total eligible discharges from the province's 93 acute care inpatient facilities during this period. The survey response rate was $73.3 \%$, as per the following formula:

[(Number of complete surveys)/

(number of complete surveys + refusals) $] \times 100$

As per the HCAHPS sampling protocol, ${ }^{26}$ we excluded patients who were under 18 years, had an inpatient stay $<24$ hours, died during hospital stay, were admitted to a psychiatric unit, had a psychiatric physician consultation or had day surgery or ambulatory procedures. For compassionate reasons, our organisation also excluded visits relating to stillbirths, dilation and curettage (D\&C) procedures, or linked to a newborn with length of stay $>6$ days (eg, complication/neonatal intensive care unit stay). ${ }^{27} \mathrm{~A}$ list of eligible patients was generated on a bi-weekly basis from administrative discharge data for each of the 93 hospitals. These data contained up to two telephone contact numbers for each patient, as provided at hospital admission. The data did not differentiate between mobile phones and landlines. Each hospital 
had a preset monthly quota of complete surveys. This quota corresponded to $5 \%$ of eligible discharges.

\section{Survey of inpatient experience}

Interviewers followed a standard script with a list of prompts and frequently asked questions and captured data via computer-assisted telephone interview (CATI). Of the 51 survey questions, 32 were from HCAHPS. These items measured nine standard domains: communication with doctors, communication with nurses, responsiveness of hospital staff, pain management, communication about medicines, discharge information, cleanliness of the hospital environment, quietness of the hospital environment and transition of care. Detailed information about the development, validity and American results from HCAHPS is publicly available. ${ }^{23} 28$ The remaining 19 questions addressed organisationspecific policies and procedures such as patient concerns, pharmacy care and patient education. Each survey required 15-20 min to complete.

Interviewers received standard training and conducted random dialling. Each target telephone number was dialled up to nine times on varying days and times. Calls were completed from 9:00 to 21:00 Monday to Friday, and from 10:00 to 16:00 on Saturdays. In total, $10 \%$ of phone calls were monitored as per our own institutional and HCAHPS quality assurance standards. ${ }^{26}$ To ensure responses were based on a specific inpatient visit, each interview began with a verification of the discharge date and hospital name. Respondents were asked to not consider any other healthcare interactions that they may have had during that time. At the end of the survey, patients with a concern, complaint or compliment about their healthcare services were provided with contact information for our organisation's Patient Relations department.

\section{Ethics and consent}

Ethical approval for the study was obtained from the Conjoint Health Research Ethics Board (CHREB) at the University of Calgary (file number REB14-2338). A waiver of consent was granted by the ethics board due to retrospective nature of the study. As part of the telephone survey protocol, patients were informed of the possibility that their data could be used for quality assurance and/or research purposes.

\section{Data linkage and defining patient safety indicators}

Survey data were linked to the corresponding inpatient discharge abstract data (DAD $)^{29} \quad 30$ using personal health number, facility code and discharge date. A total of 25098 surveys containing complete data were accurately linked to their corresponding inpatient record-a 91.3\% rate. Coders with professional college training on clinical information coding at all hospitals in Alberta coded demographic information, up to 25 diagnoses and 20 procedures from charts after discharge. Diagnoses were coded using the ICD-10-CA system. For
Box 1 List of documented patient safety indicators (PSIs)

- Haemorrhagic events;

- Obstetrical complications affecting the mother and/or fetus;

- Complications directly related to surgery;

- Hospital-acquired infections;

- Respiratory complications;

- Cardiac complications;

- Events proximally threatening to life or to major vital organs;

- Gastrointestinal;

- Traumatic injuries (non-procedural) arising in hospital;

- Central nervous system complications;

- Delirium;

- Drug-related adverse events;

- Adverse events related to fluid management;

- Venous thromboembolic events;

- Anaesthesia-related complications;

- Endocrine and metabolic complications;

- Decubitus ulcer.

each diagnosis, timing of the condition occurrence was also coded. Presence of PSIs was determined using an ICD-10-CA coding algorithm (DA Southern et al. Submitted) containing 17 categories of complications. The algorithm was applied to the DAD to identify diagnoses with 'type $2^{29}$ and also clinically meaningful patient safety-related events. PSIs were coded as present (one or more events) versus absent (no events). The complete list of specific PSIs which were documented is presented in box 1 .

\section{Study variables}

Demographic variables included age group at hospital discharge, sex, marital status, education level and birth location of the patient (Canada vs other). Patient age groups were classified as 18-29 (years), 30-39, 40-49, $50-59,60-69,70-79,80$ and older. Marital status was coded as single (never married), married/common law/ living with partner and divorced/separated/widowed. Education level was coded as elementary or junior high, senior high, college/technical school, undergraduate level and postgraduate degree complete. Clinical variables were PSI presence, admission type (urgent vs elective), most responsible provider service (family practitioner vs other), discharge disposition (discharged home with/without support vs other) and number of medical comorbidities. Comorbidity profiles were generated according to the Charlson Comorbidity Index ${ }^{31}$ using a validated administrative data algorithm. ${ }^{32}$ The number of comorbidities was classified as none, one, two or more.

Dependent variables included three HCAHPS questions pertaining to overall, physician and nurse rating. These three questions were read to patients as follows:

- Using any number from 0 to 10 , where 0 is the worst hospital possible and 10 is the best hospital possible, what number would you use to rate this hospital during your stay? 
- Using any number from 0 to 10 , where 0 is the worst possible doctor care and 10 is the best possible doctor care, what number would you give the care you got from all the doctors who treated you?

- Using any number from 0 to 10 , where 0 is the worst possible nursing care and 10 is the best possible nursing care, what number would you give the care you got from all the nurses who treated you?

Each question was scored on an 11-point Likert scale from 0 (worst possible) to 10 (best possible). For reporting purposes, responses were classified as high ratings (9-10) (top box) versus low (0-8) ('middle box' and 'bottom box') ratings. This is concurrent with current HCAHPS reporting standards in the USA, where 'top box' represents the most positive response choice(s) for a given question. ${ }^{33}$

\section{Statistical analysis}

Study populations were characterised using descriptive statistics. Frequencies of PSIs were calculated for overall (presence of at least one PSI) and each of the 17 individual PSIs. Demographic and clinical differences between those with and without a PSI were assessed using $\chi^{2}$ analyses. Logistic regression was performed to assess the relationship between PSIs and other demographic/clinical factors, and the overall, physician and nurse top box ratings. All analyses were performed using SAS V.9.3 (SAS Institute, Cary, North Carolina, USA). In all cases, statistical significance was determined a priori as an $\alpha$ level of 0.05 .

\section{RESULTS}

The mean age of patients was 53.3 years (range $=18$ 101), $65.3 \%$ were females, $70.0 \%$ were married or living common law/with a partner and $85.7 \%$ were born in Canada. The mean length of hospital stay was 5.3 days (median=3.0). A majority of patients were admitted to hospital on an urgent basis $(59.8 \%)$ and discharged home with or without support $(95.4 \%)$. Overall, physician and nurse care top box ratings (scores of 9 or 10 out of 10 ) were given by $61.9 \%, 73.7 \%$ and $66.1 \%$ of patients, respectively (figure 1). A total of 1085 patients $(4.3 \%)$ had at least one documented PSI in their inpatient record. A total of 1914 PSIs were documented. PSIs most frequently documented were haemorrhagic events ( $\mathrm{n}=502 ; 2.0 \%$ of sample), events relating to obstetrics $(n=373 ; 1.5 \%)$, surgical-related events $(n=248$; $1.0 \%)$ and infection $(\mathrm{n}=211 ; 0.8 \%)$. All other PSIs were present in $<0.5 \%$ of the study cohort. Patients experiencing at least one PSI during their hospital stay were more likely to be female, 18-39 years of age, highly educated and admitted to hospital on an elective basis (table 1).

Table 2 contains the results of the adjusted logistic regression analyses. For overall experience, having one or more PSIs was associated with decreased odds of reporting an overall top box score. Respondents who were married/common law/living with a partner, those with an education level of college/technical school or less, having a family practitioner as the most responsible provider service and being discharged home with/ without support showed increased odds. Decreased odds of having a top box score (ie, having a less than optimal hospital experience) was seen among those 18-69 years of age (compared with 80 years and older), being born in Canada, those admitted on an urgent basis and among those with two or more Charlson comorbidities.
Figure 1 Distribution of responses to overall, nurse and physician ratings of care.

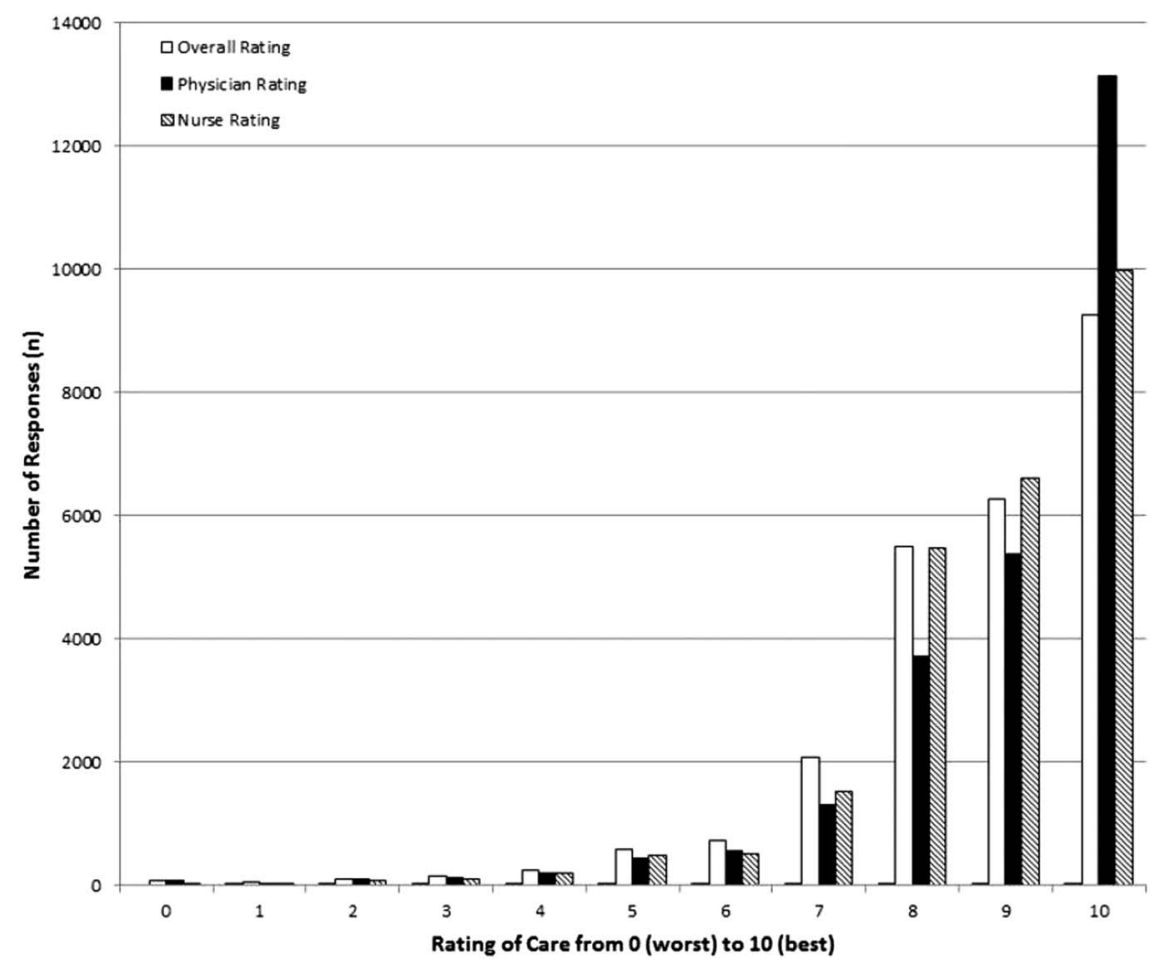


Table 1 Demographic and clinical characteristics of sample

\begin{tabular}{|c|c|c|c|c|c|}
\hline Variable & Total $\mathbf{n}$ & $\%$ of total sample & No PSI & $\geq 1 \mathrm{PSI}$ & p Value \\
\hline Rating of overall care & & & & & 0.0061 \\
\hline 9 or 10 (top box) & 15542 & 61.9 & 62.1 & 58.0 & \\
\hline 0-8 (middle and bottom boxes) & 9556 & 38.1 & 37.9 & 42.0 & \\
\hline Rating of physician care & & & & & 0.0009 \\
\hline 9 or 10 (top box) & 18504 & 73.7 & 73.9 & 69.4 & \\
\hline 0-8 (middle and bottom boxes) & 6594 & 26.3 & 26.1 & 30.6 & \\
\hline Rating of nurse care & & & & & 0.0007 \\
\hline 9 or 10 (top box) & 16604 & 66.2 & 66.4 & 61.4 & \\
\hline 0-8 (middle and bottom boxes) & 8494 & 33.8 & 33.6 & 38.6 & \\
\hline Sex & & & & & 0.0001 \\
\hline Male & 9360 & 34.7 & 35.0 & 29.3 & \\
\hline Female & 17342 & 65.3 & 65.0 & 70.7 & \\
\hline Age (in years) & & & & & $<0.0001$ \\
\hline $18-29$ & 4085 & 16.3 & 16.1 & 20.3 & \\
\hline 30-39 & 3926 & 15.6 & 15.5 & 18.7 & \\
\hline $40-49$ & 2606 & 10.4 & 10.5 & 8.5 & \\
\hline $50-59$ & 3880 & 15.5 & 15.6 & 12.0 & \\
\hline $60-69$ & 4407 & 17.6 & 17.6 & 16.6 & \\
\hline $70-79$ & 3623 & 14.4 & 14.5 & 14.0 & \\
\hline 80 and older & 2571 & 10.2 & 10.3 & 10.0 & \\
\hline Marital status & & & & & $<0.0001$ \\
\hline Single (never married) & 2580 & 10.3 & 10.4 & 6.8 & \\
\hline Married/common law/living with partner & 17559 & 70.0 & 69.7 & 75.4 & \\
\hline Divorced/separated/widowed & 4959 & 19.2 & 19.9 & 17.8 & \\
\hline Education level & & & & & $<0.0001$ \\
\hline Elementary or junior high & 3215 & 12.8 & 12.9 & 9.0 & \\
\hline Senior high (some or complete) & 8264 & 32.9 & 33.0 & 32.4 & \\
\hline College/technical school (some or complete) & 8228 & 32.8 & 32.8 & 32.4 & \\
\hline Undergraduate level (some or complete) & 4255 & 17.0 & 16.8 & 20.3 & \\
\hline Postgraduate degree complete & 1071 & 4.5 & 4.5 & 6.0 & \\
\hline Patient born in Canada & & & & & $<0.0001$ \\
\hline Yes & 21505 & 85.7 & 85.9 & 80.3 & \\
\hline No & 3593 & 14.3 & 14.1 & 19.7 & \\
\hline Admission type & & & & & $<0.0001$ \\
\hline Urgent & 15019 & 59.8 & 60.6 & 42.4 & \\
\hline Elective & 10079 & 40.2 & 39.4 & 57.6 & \\
\hline Most responsible provider service & & & & & $<0.0001$ \\
\hline Family practitioner & 12704 & 50.6 & 51.3 & 35.8 & \\
\hline Other & 12394 & 49.4 & 48.7 & 64.2 & \\
\hline Discharge disposition & & & & & 0.1592 \\
\hline Discharged home with/without support & 23931 & 95.4 & 95.4 & 94.5 & \\
\hline Other & 1167 & & 4.6 & 4.6 & 5.5 \\
\hline Charlson comorbidities & & & & & $<0.0001$ \\
\hline 0 & 18041 & 71.9 & 72.0 & 68.9 & \\
\hline 1 & 4918 & & 19.6 & 19.6 & 18.5 \\
\hline 2 or more & 2139 & 8.5 & 8.4 & 12.6 & \\
\hline
\end{tabular}

PSI, patient safety indicator.

For physician experience, having one or more PSIs was associated with decreased odds of a top box score. Conversely, age of 60-69 years, being married/common law/living with partner, an education level of undergraduate level or less, having a family practitioner as the most responsible provider service and being discharged home with/without support had increased odds. Decreased odds of having a top box score was associated with age of $18-59$ years, male sex, having been born in
Canada, having an urgent admission to hospital and having one or more Charlson comorbidities.

For nursing experience, having one or more PSIs was associated with decreased odds of a top box score. Male sex, being married/common law/living with partner, an education level of senior high or less, a family practitioner as the most responsible provider service and being discharged home with/without support had increased odds. Decreased odds of having a top box 
Table 2 Adjusted ORs $(95 \% \mathrm{Cl})$ for having a high overall, physician and nurse experience (9 or 10 out of 10 , 'top box' rating) during hospitalisation

\begin{tabular}{|c|c|c|c|}
\hline Variable & Overall & Physician & Nurse \\
\hline \multicolumn{4}{|l|}{ Patient safety indicators } \\
\hline 0 & 1.00 & 1.00 & 1.00 \\
\hline 1 or more & $0.86(0.75$ to 0.97$)$ & 0.76 (0.66 to 0.87$)$ & $0.83(0.73$ to 0.94$)$ \\
\hline \multicolumn{4}{|l|}{ Age (in years) } \\
\hline $18-29$ & $0.51(0.45$ to 0.57$)$ & $0.61(0.53$ to 0.70$)$ & 0.64 (0.56 to 0.72$)$ \\
\hline $30-39$ & 0.51 (0.45 to 0.57$)$ & 0.61 (0.53 to 0.69$)$ & $0.62(0.55$ to 0.70$)$ \\
\hline $40-49$ & 0.59 (0.52 to 0.67$)$ & $0.71(0.62$ to 0.80$)$ & 0.76 (0.67 to 0.86$)$ \\
\hline $50-59$ & $0.67(0.60$ to 0.75$)$ & $0.84(0.75$ to 0.95$)$ & 0.88 (0.79 to 0.99$)$ \\
\hline $60-69$ & $0.87(0.78$ to 0.97$)$ & $1.20(1.07$ to 1.36$)$ & 1.07 (0.95 to 1.19$)$ \\
\hline $70-79$ & 0.91 (0.81 to 1.02$)$ & 1.08 (0.96 to 1.22$)$ & 1.04 (0.93 to 1.17$)$ \\
\hline 80 and older & 1.00 & 1.00 & 1.00 \\
\hline \multicolumn{4}{|l|}{ Sex } \\
\hline Male & $1.01(0.95$ to 1.07$)$ & 0.86 (0.81 to 0.92$)$ & $1.07(1.01$ to 1.14$)$ \\
\hline Female & 1.00 & 1.00 & 1.00 \\
\hline \multicolumn{4}{|l|}{ Marital status } \\
\hline Single (never married) & $0.99(0.89$ to 1.10$)$ & $1.01(0.90$ to 1.14$)$ & $0.93(0.83$ to 1.04$)$ \\
\hline Married/common law/living with partner & 1.09 (1.02 to 1.17$)$ & $1.20(1.11$ to 1.30$)$ & 1.14 (1.06 to 1.22$)$ \\
\hline Divorced/separated/widowed & 1.00 & 1.00 & 1.00 \\
\hline \multicolumn{4}{|l|}{ Education level } \\
\hline Elementary or junior high & 1.75 (1.51 to 2.02$)$ & $1.52(1.30$ to 1.78$)$ & $1.33(1.14$ to 1.54$)$ \\
\hline Senior high (some or complete) & 1.46 (1.28 to 1.66$)$ & 1.47 (1.28 to 1.69$)$ & $1.23(1.08$ to 1.41$)$ \\
\hline College/technical school (some or complete) & $1.22(1.08$ to 1.39$)$ & $1.22(1.07$ to 1.41$)$ & $1.06(0.93$ to 1.21$)$ \\
\hline Undergraduate level (some or complete) & $1.11(0.97$ to 1.27$)$ & $1.17(1.01$ to 1.35$)$ & 1.04 (0.91 to 1.20$)$ \\
\hline Postgraduate degree complete & 1.00 & 1.00 & 1.00 \\
\hline \multicolumn{4}{|l|}{ Patient born in Canada } \\
\hline Yes & $0.84(0.78$ to 0.91$)$ & $0.89(0.82$ to 0.97$)$ & $0.97(0.90$ to 1.05$)$ \\
\hline No & 1.00 & 1.00 & 1.00 \\
\hline \multicolumn{4}{|l|}{ Admission type } \\
\hline Urgent & $0.78(0.73$ to 0.83$)$ & $0.62(0.58$ to 0.66$)$ & $0.87(0.82$ to 0.93$)$ \\
\hline Elective & 1.00 & 1.00 & 1.00 \\
\hline \multicolumn{4}{|l|}{ Most responsible provider service } \\
\hline Family practitioner & $1.18(1.11$ to 1.25$)$ & $1.09(1.02$ to 1.16$)$ & $1.09(1.03$ to 1.15$)$ \\
\hline Other & 1.00 & 1.00 & 1.00 \\
\hline \multicolumn{4}{|l|}{ Discharge disposition } \\
\hline Discharged home with/without support & $1.34(1.18$ to 1.51$)$ & $1.30(1.14$ to 1.48$)$ & 1.16 (1.03 to 1.32$)$ \\
\hline Other & 1.00 & 1.00 & 1.00 \\
\hline \multicolumn{4}{|l|}{ Charlson comorbidities } \\
\hline 0 & 1.00 & 1.00 & 1.00 \\
\hline 1 & $0.96(0.89$ to 1.03$)$ & $0.90(0.84$ to 0.98$)$ & $0.92(0.85$ to 0.99$)$ \\
\hline 2 or more & $0.83(0.75$ to 0.97$)$ & 0.76 (0.66 to 0.87$)$ & 0.73 (0.65 to 0.80$)$ \\
\hline
\end{tabular}

score was associated with age of 18-59 years, having an urgent admission to hospital and having one or more Charlson comorbidities.

Figure 2 highlights the odds from stratified analyses, according to gender, age group and number of comorbidities. Most notably, males with a PSI consistently showed decreased odds of having top box scores for overall, physician and nurse care. Females, certain age groups (particularly those 50 years and older) and patients with comorbidities who also had a PSI showed similar decreased odds.

\section{DISCUSSION}

Presence of at least one PSI was associated with decreased odds of having top box HCAHPS ratings of overall, physician and nurse care. This was also shown in risk-adjusted models which controlled for a number of demographic and clinical characteristics. Age, marital status, education level, admission type, most responsible provider service, discharge disposition and number of comorbidities were related to patient experience ratings -replicating previous findings by our group. ${ }^{27}$ Perhaps most important, our results suggest that when reported as a summarised, system-level performance measure, patient-reported experience is associated with PSIs, one element of quality of care. The association between patient experience and elements of care quality had been shown previously in a study by Isaac et al. They demonstrated that positive experiences were associated with fewer inpatient complications, particularly pressure 
Figure 2 Stratified analyses for PSI presence and 'top box' ratings of care, according to gender, age group and number of medical comorbidities. PSI, patient safety indicator.

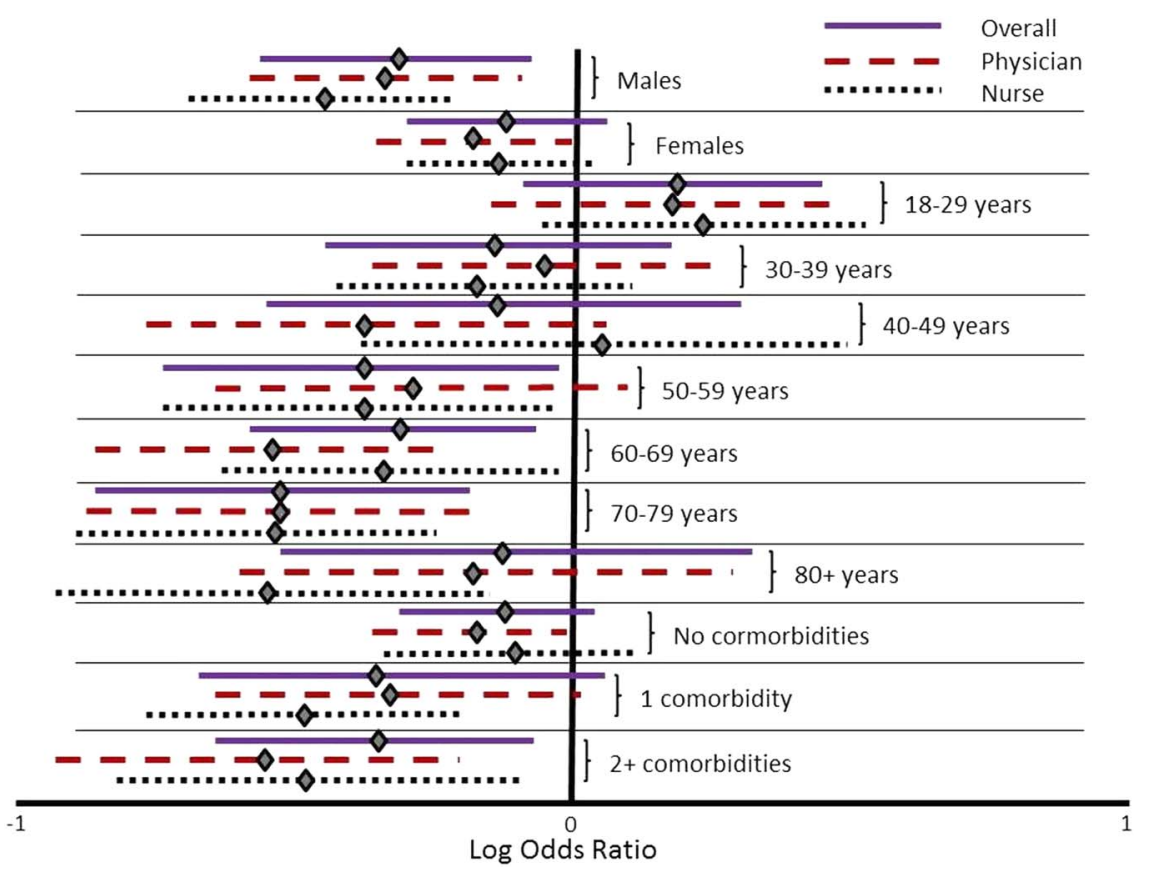

ulcers, postoperative respiratory failure and pulmonary embolism/deep vein thrombosis. ${ }^{34}$ Similarly, hospitals with patients who report more positive care experiences have been shown to have employees with more positive perceptions of patient safety culture. ${ }^{35-37}$ Our study expands upon these findings, using a validated algorithm for documenting a wide range of PSIs. ${ }^{32}$ Additionally, our results had not been previously demonstrated using an HCAHPS-based instrument in a Canadian setting-one with universal Medicare coverage.

We suggest that a standardised measure of patient experience should be used as an indicator of PCC and to monitor healthcare system performance. This is an area of research that has been to date largely untouched. One advantage of patient experience, as captured via HCAHPS, is that a direct report is provided by the patient using a validated instrument. This provides opportunities for valid comparisons across hospitals and healthcare organisations, particularly when using case-mix and mode adjustment to account for demographic, survey administration (eg, mail vs phone) and service-level differences. ${ }^{38}$ It should also be noted that the HCAHPS validation process used patients from the outset-allowing for an accurate reflection of what is deemed important from patients themselves.

There are many opportunities for future use of inpatient experience data. Communication between clinicians and patients plays an important role in PCC. This reflects a somewhat fundamental change in the perspective of physician-patient interaction. Within the context of PCC, physicians do not make treatment decisions on behalf of the patient, but rather in conjunction with the patient. This encourages transparency as well as the incorporation of the patient's values, beliefs and choices throughout their care journey. In their review of patient perceptions of healthcare quality, Sofaer and Firminger conclude with the following statement: 'If we are truly to achieve a healthcare system that is patient-centered, we must continue to search for creative ways to elicit, and heed, the voice of the patient'. ${ }^{39}$

The present study has several strengths. It is the first to link Canadian inpatient experience data to PSIs using an ICD-10-CA algorithm. In their 2013 commentary, Manary et $a t^{40}$ made a series of recommendations to further validate comparisons of patient experience and outcomes. These were that future said comparisons should (1) focus on a specific event or visit, (2) focus on patientprovider interactions, (3) ensure the timeliness of the measure to limit recall bias and (4) perform risk adjustment. The present project satisfies all four of these criteria.

Another strength is that the survey was conducted using a validated instrument (eg, HCAHPS), with a standard script, prompts and answers to frequently asked questions. These help ensure the highest degree of standardisation and reliability, as compared to historical investigations of patient experience, which have primarily used ad hoc instruments.

Additionally, the quality and breadth of our abstracted data is a tremendous asset. As the sole provider of provincial inpatient healthcare services, Alberta Health Services has complete documentation on all inpatient visits that occur in our jurisdiction. Thus, the potential for data linkage is great as no gaps in data coverage will occur. This overcomes a huge limitation present in other jurisdictions that do not have a universal healthcare model.

The final study strength lies within our comprehensive survey sampling strategy. As opposed to cherry-picking patients, the sample is derived from all eligible inpatient discharges. Thus, each potential participant has an equal chance of participation, regardless of institution, date of service or clinical condition. Contact information includes up to two telephone numbers provided at the 
time of hospital registration, thus are presumed to be the most accurate way of contacting patients. Contact is attempted up to nine times at varying times over varying days, including one weekend day. Patients unable to speak freely are provided with an opportunity to book a call-back time, at their convenience. Our high response rate $(73 \%)$ and representativeness of the sample ${ }^{41}$ demonstrate the success of these strategies.

There are some limitations to the present study which warrant discussion. The first is that PSI represents only one aspect of quality of care. Other aspects (eg, medication adherence, readmission rate) may have a different relationship with patient experience. Second, although administrative data alone may not capture all PSIs ${ }^{21}$ (DA Southern, et al. Submitted), several validation studies document their accepted use as a quality indicator, including ones by the Agency for Healthcare Research and Quality (AHRQ). Third, it has been postulated that to accurately obtain an educated assessment of patient experience, it is necessary to educate patients a priori regarding appropriate expectations of care. ${ }^{42}$ In our opinion, we feel that this would be an excellent topic for future research. Fourth, due to the cross-sectional nature of our study, we advocate caution in interpreting the study results. These should be considered as associative only, and causality should not be inferred. As in previous work by our group, ${ }^{27}$ there were many other factors (eg, demographic, clinical) that were associated with high experience ratings. Although these were controlled for in the present study, we did not perform any case-mix adjustment, as is done in the USA. ${ }^{43}$ Last, as this was a Canadian study, results may vary in other jurisdictions, particularly those with differing healthcare models (eg, UK, USA).

In conclusion, the present study demonstrates a clear association between patient-reported hospital experience and an element of healthcare quality, via documentation of PSIs using administrative data. The study has a clear policy implication, as we have demonstrated that subjective patient accounts are associated with an objective element of care quality. Showing that patients can accurately report what took place in hospital lends further support to the inclusion of patient experience as a measure of health system performance. This also supports the documentation of patient experience for quality improvement purposes. Future research, examining individual PSIs and specific patient experience questions, is warranted, as certain aspects of care may be closely associated with AEs. The association of other aspects of quality of care with patient experience should also be examined. Last, future studies which include in-depth interviews and a measure of patient expectations may provide additional insight regarding how patients rate their hospital experience.

Acknowledgements The authors acknowledge the team of Health Research Interviewers from Primary Data Support, Analytics (DIMR), Alberta Health Services, as well as the patients who completed the survey.
Contributors KAK, MJS and HQ developed the research question and study methods. Data collection, linkage and analysis were performed by KAK, BMC, MJS and $\mathrm{HQ}$. All authors contributed to the drafting and editing of the manuscript, including approval of the final version submitted for publication.

Funding This research received no specific grant from any funding agency in the public, commercial or not-for-profit sectors.

Competing interests None declared.

Ethics approval University of Calgary Conjoint Health Research Ethics Board (CHREB) approved the study and provided a waiver of consent (file number REB14-2338).

Provenance and peer review Not commissioned; externally peer reviewed.

Data sharing statement No additional data are available.

Open Access This is an Open Access article distributed in accordance with the Creative Commons Attribution Non Commercial (CC BY-NC 4.0) license, which permits others to distribute, remix, adapt, build upon this work noncommercially, and license their derivative works on different terms, provided the original work is properly cited and the use is non-commercial. See: http:// creativecommons.org/licenses/by-nc/4.0/

\section{REFERENCES}

1. Committee on Quality of Health Care in America, Institute of Medicine. Crossing the Quality Chasm: A new health system for the 21st century. Washington DC: National Academy Press, 2001.

2. Patient-Centered Outcomes Research Institute. Home Page. http://www.pcori.org (accessed 30 Sep 2015).

3. Canadian Institutes of Health Research. Strategy for Patient-Oriented Research (SPOR). http://www.cihr-irsc.gc.ca/e/ 41204.html (accessed 30 Sep 2015).

4. Davies E, Shaller D, Edgman-Levitan S, et al. Evaluating the use of a modified CAHPS $\otimes$ survey to support improvements in patient-centred care: lessons from a quality improvement collaborative. Health Expect 2008;11:160-76.

5. Kennedy GD, Tevis SE, Kent KC. Is there a relationship between patient satisfaction and favorable outcomes? Ann Surg 2014;260:592-8; discussion 598-600.

6. Fenton JJ, Jerant AF, Bertakis KD, et al. The cost of satisfaction: a national study of patient satisfaction, health care utilization, expenditures, and mortality. Arch Intern Med 2012;172:405-11.

7. Glickman SW, Boulding W, Manary M, et al. Patient satisfaction and its relationship with clinical quality and inpatient mortality in acute myocardial infarction. Circ Cardiovasc Qual Outcomes 2010;3:188-95.

8. Jha AK, Orav EJ, Zheng J, et al. Patients' perception of hospital care in the United States. N Engl J Med 2008;359:1921-31.

9. Boulding W, Glickman SW, Manary MP, et al. Relationship between patient satisfaction with inpatient care and hospital readmission within 30 days. Am J Manag Care 2011;17:41-8.

10. Stein SM, Day M, Karia R, et al. Patients' perceptions of care are associated with quality of hospital care: a survey of 4605 hospitals. Am J Med Qual 2015;30:382-8.

11. Weissman JS, Lopez L, Schneider EC, et al. The association of hospital quality ratings and adverse events. Int $J$ Qual Health Care 2014:24:129-35.

12. Black N, Varaganum $M$, Hutchings $A$. Relationship between patient experience (PREMs) and patient reported outcomes (PROMs) in elective surgery. BMJ Qual Saf 2014;23:534-42.

13. Doyle $C$, Lennox L, Bell D. A systematic review of evidence on the links between patient experience and clinical safety and effectiveness. BMJ Open 2013;3:pii: e001570.

14. Wolf JA. Patient experience, satisfaction not one and the same. http://www.hospitalimpact.org/index.php/2014/07/24/patient satisfaction experience not one (accessed $22 \mathrm{Apr} 2016$ ).

15. Iezzoni $\mathrm{LI}$, Daley J, Heeren $\mathrm{T}$, et al. Identifying complications of care using administrative data. Med Care 1994;32:700-15.

16. Agency for Healthcare Research and Quality. Patient Safety Indicators Overview. http://qualityindicators.ahrq.gov/Modules/psi overview.aspx (accessed 4 May 2015).

17. McLoughlin V, Millar J, Mattke S, et al. Selecting indicators for patient safety at the health system level in OECD countries. Int $J$ Qual Health Care 2006;18(Suppl 1):14-20.

18. Rosen AK, Rivard P, Zhao S, et al. Evaluating the patient safety indicators: how well do they perform on Veterans Health Administration data? Med Care 2005;43:873-84. 
19. Coffey RM, Andrews RM, Moy E. Racial, ethnic, and socioeconomic disparities in estimates of AHRQ patient safety indicators. Med Care 2005;43(Suppl 3):148-57.

20. Romano PS, Chan BK, Schembri ME, et al. Can administrative data be used to compare postoperative complication rates across hospitals? Med Care 2002;40:856-67.

21. Quan $\mathrm{H}$, Eastwood C, Cunningham $\mathrm{CT}$, et al. Validity of $\mathrm{AHRQ}$ patient safety indicators derived from ICD-10 hospital discharge abstract data (chart review study). BMJ Open 2013;3:e003716.

22. Centers for Medicare and Medicaid Services. HCAHPS Fact Sheet. http://www.hcahpsonline.com/files/August $\% 202013 \% 20$ HCAHPS\% 20Fact\%20Sheet2.pdf (accessed 7 Oct 2014).

23. Darby C, Hays RD, Kletke P. Development and evaluation of the CAHPS hospital survey. Health Serv Res 2005;40:1973-6.

24. Goldstein E, Farquhar M, Crofton C, et al. Measuring hospital care from the patients' perspective: an overview of the CAHPS hospital survey development process. Health Serv Res 2005;40: 1977-95.

25. Forster AJ, Murff HJ, Peterson JF, et al. Adverse drug events occurring following hospital discharge. J Gen Intern Med 2005;20:317-23.

26. Centers for Medicare and Medicaid Services. Introduction to HCAHPS Survey Training. http://hcahpsonline.com/Files/March\% $202014 \% 20$ HCAHPS\%20Introduction\%20Training $\% 20$ Slides $\%$ 20Session\%20I_3_3_14.pdf (accessed 17 Dec 2014).

27. Kemp KA, Chan N, McCormack B, et al. Drivers of inpatient hospital experience using the HCAHPS survey in a Canadian setting. Health Serv Res 2015;50:982-7.

28. Centers for Medicare and Medicaid Services. CAHPS $($ Hospita Survey. http://www.hcahpsonline.org (accessed 8 Dec 2014).

29. Canadian Institute for Health Information. CIHI data quality study of the 2009-2010 discharge abstract database. https://secure.cihi.ca/ free_products/Reabstraction_june19revised_09_10_en.pdf (accessed 27 Feb 2014).

30. Canadian Institute for Health Information. Discharge Abstract Database (DAD) Metadata. http://www.cihi.ca/cihi-ext-portal/internet/ en/document/types+of+care/hospital+care/acute+care/dad_metadata (accessed 27 Feb 2014).
31. Charlson ME, Pompei P, Ales KL, et al. A new method of classifying prognostic comorbidity in longitudinal studies: development and validation. J Chronic Dis 1987;40:373-83.

32. Quan $\mathrm{H}$, Sundararajan V, Halfon $\mathrm{P}$, et al. Coding algorithms for defining comorbidities in ICD-9-CM and ICD-10 administrative data. Med Care 2005;43:1130-9.

33. Centers for Medicare and Medicaid Services. A note about HCAHPS "boxes". http://www.hcahpsonline.org/SummaryAnalyses.aspx (accessed 18 Apr 2016).

34. Isaac T, Zaslavsky AM, Cleary PD, et al. The relationship between patients' perception of care and measures of hospital safety and quality. Health Serv Res 2010;45:1024-40.

35. Lyu H, Wick EC, Housman M, et al. Patient satisfaction as a possible indicator of quality surgical care. JAMA Surg 2013;148:362-7.

36. Sorra J, Khanna K, Dyer N, et al. Exploring relationships between patient safety culture and patients' assessment of hospital care. $J$ Patient Saf 2012;8:131-9.

37. Anhang Price R, Elliott MN, Zaslavsky AM, et al. Examining the role of patient experience surveys in measuring health care quality. Med Care Res Rev 2014;71:522-54.

38. Elliott MN, Zaslavsky AM, Goldstein E, et al. The effects of survey mode, patient mix, and nonresponse on CAHPS hospital survey scores. Health Serv Res 2009;44:501-18.

39. Sofaer S, Firminger K. Patient perceptions of the quality of health services. Annu Rev Public Health 2005;26:513-59.

40. Manary MP, Boulding W, Staelin R, et al. The patient experience and health outcomes. N Engl J Med 2013;368:201-3.

41. Kemp KA, Chan N, McCormack B. The Alberta inpatient experience survey: representativeness of sample and initial findings. Survey Prac 2015;8. http://surveypractice.org/index.php/SurveyPractice/ article/view/291/pdf 30

42. Crow R, Gage H, Hampson S, et al. The measurement of satisfaction with healthcare: implications for practice from a systematic review of the literature. Health Technol Assess 2002;6:1-244

43. O'Malley AJ, Zaslavsky AM, Elliott MN, et al. Case-mix adjustment of the CAHPS hospital survey. Health Serv Res 2005;40:2162-81. 